\title{
Extensible Strategies and Their Performance for Mental Health Education in Colleges
}

\author{
https://doi.org/10.3991/ijet.v15i09.14037 \\ Kaixin Gong \\ Beihua University, Jilin, China \\ agongkaixin@163. com
}

\begin{abstract}
Currently, mental health education in college is constrained by various factors (e.g. the complex mentality of college students). This paper mainly discusses the extensible strategies for mental health education of college students, and develops a performative analysis model of these extensible strategies. Firstly, the problems in mental health education of college students were enumerated, and an extension model was set up for mental health education in colleges. On this basis, the extensible strategies were generated for college mental health education. Then, a performance analysis model was presented to effectively select and optimize the extensible strategies. The research results provide a theoretical guide for solving complex problems with extension strategy and promoting mental health education in colleges.
\end{abstract}

Keywords-Mental health education, college students, extensible strategies, performance analysis, extension theory

\section{$1 \quad$ Introduction}

With the growing standard of living, modern people are attaching more importance to spirituality and culture. This has posed a great challenge: if the growing spiritual and cultural demand is not satisfied, many might suffer from mental health problems [1-2]. The challenge is particularly serious in colleges. Many college students are subjected to two types of pressures: the growth pressure from academics, work and self-development, and the economic pressure from the society and families. The dual pressure is very detrimental to the mental health of college students [3-5].

In modern times, higher education aims to train high-level talents with a variety of abilities. Therefore, the training program should pursue all-round development. The mental health must be highlighted in the program, in addition to traditional disciplines like morality, intelligence and aesthetics. Mental health education could improve the mentality of college students, preparing them for later careers [6-8].

The mental health education of college students has been analyzed from multiple angles. For instance, Zhang and Wang [9] constructed a network model for mental health education in colleges in the context of the Internet Plus. From internal and external perspectives, Laura et al. [10] examined the barriers and supports to the participation of college students with mental health difficulties, suggesting that the dif- 
ferences between these students in academic adaptation must be solved to overcome the discriminatory attitudes and barriers to participation. Sarah Ketchen et al. [11] surveyed over 40,000 students of color from 60 colleges, and discussed their mental health status, including incidence and treatment of mental problems. Song [12] investigated the problems in mental health education of college students in the new era, and proposed countermeasures to these problems. Taking a vocational college as example, Yang and Lin [13] explored the reform of mental health education based on mental quality expansion training. Sontag-Padilla et al. [14] attempted to enhance the mental health knowledge, awareness and helping behaviors of college students. Sarmento [15] probed into the mental health status of college students through sample survey.

There is a major defect with the current studies on mental health education of college students: these studies only focus on the local links rather than the overall situation of mental health education in colleges, failing to provide extensible strategies for the problems in the education process. To solve the defect, it is necessary to develop and implement targeted extensible strategies. Based on the relevant literature and the extension theory [16-19], this paper mainly studies the extensible strategies and their performance for mental health education in colleges. The research focuses on the generation and model analysis of key extensible strategies.

The remainder of this paper is organized as follows: Section 2 enumerates the problems in mental health education of college students; Section 3 establishes an extension model for mental health education in colleges; Section 4 discusses the extensible strategies for college mental health education; Section 5 analyzes the performance of the extensible strategies; Section 6 puts forward the conclusions.

\section{Problems in Mental Health Education of College Students}

\subsection{Mismatching of mental health education concepts in colleges}

The 21st century is an era of knowledge. With the continuous development of science and technology, people's demands for high-level social, cultural, and spiritual life have been increasing, and the mainstream form of social development has tended to be people-oriented. As high-level talents, the college students' needs or perceptions of high-level socio-cultural and spiritual life are often diverse and complicated, which is ahead of most individuals in the society. Therefore, the mental health problems of college students become more prominent. Generally, the traditional college educational concepts only focus on the educational ideas and methods of knowledge transfer and absorption, but ignoring the transformation of scientific knowledge into the comprehensive ability of college students in the process of higher education, and failing to effectively handle the interaction, dialectical unity and harmonious development of knowledge, abilities and qualities in the overall structure of talents. This has led to the fact that the mental health education of college students cannot truly be people-oriented, and there are also some limitations in the training their personal qualities like confidence, self-reliance, self-improvement, and self-love, etc., in the training of their moral, intellectual, physical, aesthetic, labor and other comprehensive 
qualities, in their creativity, coordination, development, and their views of world, values and development. And from the current process of college students' mental health education, it can be found that mental health education focuses more on the evaluation of some superficial education results, and ignores the cognition of college students' psychological behavior, which is still exam-oriented education, and cannot truly provide quality education to college students. Moreover, only when the college student suffers from the mental health problem, they will think of ways to solve it, and it is only aimed at the specific problems of college students' mental health, but not to be prevented in the mental health education process of college students in advance. Thus, it's obvious that the mental health education concept of college students is lagging, and there is certain mismatching with the current society's needs for the development of college students' mental health. Therefore, in order to improve the level of mental health education in colleges, it is necessary to raise the mental health education concept of college students to a higher level.

\subsection{The backwardness of mental health education model in colleges}

By investigating and analyzing some mental health education models in colleges, it can be found that the current models are not consistent as a whole, and the overall effect is poor. Some colleges focus on the multiple educational methods, means and technologies in the implementation of mental health education models, but often fail to integrate these three well. In most cases, the relatively independent infused education model is adopted by the colleges, which is difficult to reflect the interaction and communication of mental health education for college students, and to touch their mental feelings and emotional cognition of mental health education, that is, the essence of mental health education for college students cannot be reflected in essence. In addition, there are also many limitations in the key links during the implementation of the college mental health education model, such as the curriculum setting, the development and application of educational platforms, teaching methods, and teaching means etc.: Firstly, the number of curriculums for college mental health education is often small, and it is not systematic and planned, so that the college students cannot recognize mental health systematically. In the application of intelligent technology, the mental health education of college students is relatively backward, resulting in the lack of intelligence in the development of the corresponding education platform or education system, and the difficulty of keeping up with the needs of contemporary college students. Furthermore, the teaching methods of mental health are often relatively single, and most of them are concentrated teaching, lacking flexible interactive communication. Finally, for the teaching means of mental health, traditional classroom teaching is mostly adopted, lacking the necessary dynamic, experimental, collaborative, interactive, and inquiry-based intelligent means under the support of advanced technology. All these will affect the effectiveness of mental health education in colleges. 


\subsection{Insufficient developmental of mental health education in colleges}

To sum up, the insufficient development of college students' mental health education is mainly reflected in the lack of understanding of students, educational development goals, social development status, environmental changes, and intelligent technology development: First, the lack of understanding of students mainly refers to the fact that college mental health education cannot fully consider the diversity, complexity and hierarchy of college students' psychological qualities. In the implementation process of mental health education, these inherent qualities of college students should be analyzed separately, because with the continuous improvement of students 'cultural needs and spiritual life, their impact on mental health education is also increasing. Secondly, due to the lack of understanding of educational development goals, college students' mental health education needs to be adjusted accordingly based on the transformation of higher education goal, that is, gradually transforming from traditional test-oriented education to quality education and meeting the requirements of college students' mental health training. Thirdly, the lack of understanding of social development status mainly means that the implementation of college mental health education needs to be combined with the current social development status, because the comprehensive quality training of college students must vary at different stages of social development. Fourth, for the lack of understanding of environmental change, the mental health education should be implemented according to the surrounding environment of college students, including social environment, family environment, and school environment etc. Fifth, the lack of understanding of the intelligent technology development mainly indicates that the college mental health education needs to be consistent with the level of scientific and technological development. The application of science and technology in higher education can help to cultivate more high-quality talents with better mental health, while these talents further promote the development of science and technology, thereby forming a virtuous circle.

\subsection{Low status of mental health education in colleges}

Compared with other disciplines or majors in colleges, such as computer engineering, control engineering, aerospace engineering, biological engineering, management engineering, mechanical engineering, materials engineering, etc., the mental health education is essentially at a low status, especially in some colleges mainly based on science and engineering, because their development depends on the innovation and support of engineering technology. For this, these colleges pay more attention to the cultivation of professional technical ability in related disciplines or majors, but attach little importance to the mental health education of college students. For instance, the poor infrastructure of college mental health education, insufficiency of professional faculty, team construction, and fund investment lead to a low potential for the development of college mental health education. Also, there is the lack of understanding of the mental health education; not only the college leaders or managers believe that mental health education has limited impacts on improving the comprehensive strength of the school, but also many teachers and students think that the mental health educa- 
tion is not the mainstream major for school development, so they haven't taken a positive attitude towards it. The development plan of college mental health education is not systematic and forward-looking in terms of curriculum setting, outline preparation, talent echelon construction, management system, etc., which cannot ensure a good ability of sustainable development. What's more, there exists serious formalism in the implementation of college mental health education. Although some colleges have provided relevant mental health education courses, studios or platforms, they are often mere skeletons and have not been fully integrated into student training.

\section{Construction of an Extension Model of Mental Health Education in Colleges}

\subsection{Compatibility model analysis}

From the above analysis, it can be seen that the mental health education in colleges is subjected to a variety of conditions, which makes it difficult for the college mental health education to achieve the desired goals. To obtain the ideal effect of college mental health education, it is necessary to establish an extension model of mental health education in colleges by altering these conditions and analyze the compatibility. The analysis process of the compatibility model is shown in formula (1):

$$
P_{D}\left(\boldsymbol{R}_{M H E}\right)=G_{O}\left(\boldsymbol{R}_{M H E}\right) * L_{S}\left(\boldsymbol{R}_{M H E}\right)
$$

where, $\boldsymbol{R}_{M H E}$ represents the implementer of college mental health education, which is generally characterized by its matter-element model, and $P_{D}\left(\boldsymbol{R}_{M H E}\right)$ is the matterelement model, usually expressed in the form of the problem matter-element; $G_{O}\left(\boldsymbol{R}_{M H E}\right)$ is the implementation effect that $P_{D}\left(\boldsymbol{R}_{M H E}\right)$ may or be expected to be achieve under relevant conditions, which is usually expressed in the form of a goal matter-element of mental health education in colleges; $L_{S}\left(\boldsymbol{R}_{M H E}\right)$ is the subjective and objective conditions to achieve $G_{O}\left(\boldsymbol{R}_{M H E}\right)$, including constraints and implementation conditions, usually expressed in the form of condition matter-element of college mental health education.

Based on the establishment of the compatibility model, it can be seen that the solution of college mental health education problems is essentially composed of the goal matter-elements $G_{O}\left(\boldsymbol{R}_{M H E}\right)$ and condition matter-elements $L_{S}\left(\boldsymbol{R}_{M H E}\right)$. Extension analysis can be conducted on $L_{S}\left(\boldsymbol{R}_{M H E}\right)$ from the perspective of compatibility, to obtain the corresponding solution strategies, methods or means.

\subsection{Matter-element model}

The mental health education in colleges involves multiple forms of information, which can be extracted to form the basic characteristics of extension model. To this end, the matter-element model of each analysis object was established based on ex- 
tension theory, i.e., the implementaters of college mental health education, can be expressed as:

$$
\boldsymbol{R}_{M H E}=\left[N_{M H E}, C, V\right]
$$

where, $N_{M H E}$ is the name of the matter-element model $\boldsymbol{R}_{M H E}, C$ is the features or characteristics of the $\boldsymbol{R}_{M H E}$, and $V$ is the value of the characteristics $C$.

In general, a matter-element model often contains multiple features or characteristics, so it needs to be described in the form of multiple features. Assuming that the object contains $n$ features or characteristics, its matter-element model is expressed as:

$$
\boldsymbol{R}_{M H E}=\left[\begin{array}{ccc}
N_{M H E} & C_{1} & V_{1} \\
& C_{2} & V_{1} \\
& \vdots & \vdots \\
& C_{n} & V_{n}
\end{array}\right]
$$

\subsection{Multi-level diamond thinking mode}

Based on the matter-element model established for college mental health education above, the corresponding extension analysis was performed considering the constraints. Generally, extension transformation based on the matter-element characteristics is used to obtain more new matter-elements that meet the target requirements. There may be a large number of new matter elements, and they often do not all meet the needs of problem solving. Therefore, the relevant matter elements obtained need to be screened to obtain a small number of matter elements meeting the target needs. This is essentially a process of extension-convergence. If one extension-convergence process can fulfill an ideal strategy of mental health education for college students, it is called a first-level diamond thinking mode. However, because college students' mental health education is affected by multiple factors, they often need to take the form of extension -convergence-re-extension -re-convergence ... and further form a multi-level diamond thinking mode for the implementation of college students' mental health education.

\subsection{Extension transformation}

To obtain a new matter element that solves the problem of mental health education in colleges based on the existing constraints, it is necessary to perform an extension transformation of the matter element. There are many kinds of extension transformations, including domain transformation, matter-element characteristics transformation, value transformation, combined transformation of matter-element characteristics and value, etc. Among them, the domain transformation means to solve the problem of mental health education in colleges by drawing on the knowledge of other 
related or similar subjects and specialties. The transformation of matter-element characteristics refers to the ability to add, delete, or replace the matter-element features or characteristics of $\boldsymbol{R}_{M H E}, P_{D}\left(\boldsymbol{R}_{M H E}\right), G_{O}\left(\boldsymbol{R}_{M H E}\right)$, and $L_{S}\left(\boldsymbol{R}_{M H E}\right)$, and further obtain new knowledge, methods, and means required to solve the mental health problems of college students. Value transformation means modifying the magnitude of the corresponding matter-element characteristics without changing its characteristics to meet the needs of the mental health education in colleges. The combined transformation of the matter-element characteristics and values refers to the modification of matterelement characteristics and values to meet the needs of college mental health education. Let $T$ be the extension transformation, then the domain transformation is represented by $T_{\Omega}$, the matter-element characteristics transformation is $T_{C}$, the value transformation is $T_{V}$, and the combined transformation of matter-element characteristics and values is $T_{(C, V)}$. The new matter-element process of mental health education based on extension transformation can be expressed as:

$$
\left\{\begin{array}{l}
T_{\Omega} \Omega \mid=\Omega_{i} \in\left\{\Omega \vee \Omega_{1} \vee \Omega_{2} \vee \cdots \vee \Omega_{m}\right\} \\
T_{C} \mathrm{C} \mid=C_{j} \in\left\{C \vee C_{1} \vee C_{2} \vee \cdots \vee C_{n}\right\} \\
T_{V} V \mid=V_{k} \in\left\{V \vee V_{1} \vee V_{2} \vee \cdots \vee V_{p}\right\} \\
T_{(C, V)}(C, V) \mid=(C, V)_{r} \in\left\{(C, V) \vee(C, V)_{1} \vee(C, V)_{2} \vee \cdots \vee(C, V)_{q}\right\}
\end{array}\right.
$$

where, $\Omega, C, V$, and $(C, V)$ are the domain, characteristics, value, and combination of characteristics and values of mental health education in colleges respectively, and $m, n, p$, and $q$ are the corresponding extension number of the domain, characteristics, value, and combination of characteristics and values respectively.

\section{Extensible Strategy for Mental Health Education in Colleges}

Based on the extension model above and the current problems in the mental education of college students, the problem matter-element $P_{D}\left(\boldsymbol{R}_{M H E}\right)$ is defined as the problem required to be solved for improving the college mental education ability, the goal matter-element $G_{O}\left(\boldsymbol{R}_{M H E}\right)$ means the high-level mental health education in colleges, $L_{S}\left(\boldsymbol{R}_{M H E}\right)$ is the influencing factors, and $\mathbf{R}_{\mathrm{MHE}}$ is the strategic objects during the implementation process of mental health education. Through the survey and analysis, the extensible strategy analysis was conducted on the mental health education in colleges from the aspects of education techniques, education subjects, education patterns, and education methods. Therefore, the matter-element model $\boldsymbol{R}_{M H E}$ based on its extensible strategy is expressed as: 


$$
\boldsymbol{R}_{M H E}=\left[\begin{array}{ccc}
N_{M H E} & C_{E T} & \boldsymbol{R}_{E T} \\
& C_{E O} & \boldsymbol{R}_{E O} \\
& C_{E P} & \boldsymbol{R}_{E P} \\
& C_{E M} & \boldsymbol{R}_{E M}
\end{array}\right]
$$

where, $C_{E T}, C_{E O}, C_{E P}$, and $C_{E M}$ represent the matter-element characteristics of the matter-element mode respectively, namely education technique, education subjects, education patterns, and education methods, respectively; $\boldsymbol{R}_{E T} 、 \boldsymbol{R}_{E O} 、 \boldsymbol{R}_{E P} 、 \boldsymbol{R}_{E M}$ are the values of $C_{E T}, C_{E O}, C_{E P}$, and $C_{E M}$, because each value can be specific implementation objects, and each object can build its own matter-element model and use it as a measure of matter-element characteristics.

\subsection{Extensible strategies of education techniques}

At present, the education techniques of mental health in colleges are often limited to classroom mode or studio mode. In addition to traditional forms of blackboardbased teaching, teaching tools such as projectors and cameras may be used. However, the current educational techniques are difficult to meet the target needs of mental health, so it is necessary to conduct an extensible strategy analysis. From the perspective of domain transformation, advanced science and technology such as Internet Plus, big data, information technology, network technology, etc. have relatively mature applications in other engineering fields, and even in some engineering majors of colleges. Then these technologies can be used to support college mental health education. From the perspective of characteristics transformation, the current form of mental health education based on blackboards or books can be transformed into multiple forms such as APP, self-media, and campus broadcast. From the perspective of value transformation, the current sites of mental health education in colleges can be expanded from classrooms or studios to libraries, dormitories, and student homes.

\subsection{Extensible strategies of education subjects}

College mental health education is generally implemented by the professional teachers of mental health courses or the instructors of college mental health studios. But the mental health education courses in colleges are not well planned, and the professional faculty is often insufficient, so that the guiding role of the professional teachers generally cannot be fully exerted through professional courses, affecting the mental education effect of college students. Moreover, similar problems exist in the mental health studios set up in colleges. Due to the small number of studios, the lack of instructors, and the limitation in studio's opening hours, the studio is completely unable to meet the mental health education needs of all college students. At this time, it is just possible to obtain more education objects based on the domain transformation and value transformation of matter-element model, that is, expanding the tra- 
ditional education subjects from professional class teachers and studio instructors to class teachers, counselors, dormitory administrators, classmates, students' parents, and psychologists, etc. In the current study and life of college students, the class teacher and counselor are the closest to the students, and they have a deeper understanding of their life and learning status, which is conducive to cultural exchange and learning with college students. Dormitory administrators, classmates, and student parents are more likely to establish emotional communication with college students, making them feel at home, and promoting the exchange of mental health. Psychologists can provide more professional mental health education knowledge, and implement mental health education in a targeted manner.

\subsection{Extensible strategies of education patterns}

The survey found that in addition to classroom teaching and mental health studio guidance, there is generally no other way to support and assist college mental health education, that is, the college mental health education is conducted only in specific patterns, which obviously does not meet the diversity needs of the college mental health. It is clear that the personality of college students is often different, e.g., some college students like quiet, while others like noisy; some are more psychologically extreme, while some may be more peaceful; some college students like sports or traveling, while other like reading or art. Thus, in order to obtain the desired effect of mental health education for college students, it is necessary to consider how to carry out mental health education for them according to different personal needs, because there are great limitations to use only classroom teaching and mental health studio guidance. From the perspective of characteristics transformation, the educational pattern can be changed through the optimization of mental health education curriculum or the combination of medicine and education; from the perspective of the domain transformation, it can be optimized by the improvement of physical exercise, art cultivation and appreciation, and face to face interview with celebrities; from the perspective of value transformation, book reading, spiritual communication, expert panel, and academic discussions can be used to supplement classroom teaching or studio guidance, thereby promoting the mental health education of college students.

\subsection{Extensible strategies of educational methods}

At present, the mental health education of college students is mainly based on the transfer of mental health knowledge. Such knowledge transfer is made using different methods such as the narrative method, questioning method, or discussion method, which are still the instilling knowledge-transference from the formal. In order to effectively avoid the problems existing in the mental health education mentioned above, it is urgently needed to improve the educational methods. The author used the domain transformation to learn from other types of teaching methods and implement them in the mental health education of college students. For instance, the teaching method based on direct perception can enable college students to directly perform emotional perception and communication through demonstration, and case studies, etc., making 
it easier for college students to have telepathy; the teaching methods oriented to practical exercises arouse the immersive emotional and psychological consciousness of college students through practical activities and collaborative learning, so that they can more naturally perceive the true meaning of mental health education; the teaching methods based on appreciation activities or guided inquiry can be used to organically integrate hobbies and knowledge learning to improve the mental health education ability.

\section{Performance Analysis for Extensible Strategies of Mental Health Education in Colleges}

Under the multi-level diamond thinking mode, extension transformation can be used to obtain various forms of extensible strategies for the mental health education of college students. Because of the divergence nature of the strategy, theoretically it is possible to obtain more feasible solutions under the premise of meeting the requirements of mental health education goals. But the colleges are not completely consistent and standardized in terms of the mental health education, so these solutions may not be completely applied to the mental education. This needs to be optimized and selected in combination with the actual situation of colleges, so as to obtain the extensible strategy with better results, that is, to perform an extension performance analysis of college mental health education. There are many performance analysis methods [2023], but considering that performance analysis indicators may have ambiguous positional relationships, this paper chooses the extension correlation function [24-25] for analysis.

\subsection{Index selection}

Due to different situations of mental health education in colleges, the index of their performance analysis is often diverse. From the analysis above, it can be seen that the extensible strategy should be implemented, mainly to solve the mental health problems for current college students and promote the mental health education in colleges. Therefore, the extensible strategy of college mental health education is also mainly reflected in the aspects of education techniques, education subjects, education patterns, and education methods. Accordingly, the indices of the performance analysis are also selected mainly in terms of these four aspects. The selection process should follow the principles of scientificity, objectivity, pertinence, and analyzability.

\subsection{Extension correlation analysis}

After determining the extension performance analysis index $S_{i}$ of mental health education for all colleges, an index set was formed, to be expressed as: 


$$
S=\left\{s_{1}, \cdots, s_{i}, \cdots, s_{n}\right\}, 1 \leq i \leq n
$$

The corresponding weight set of the index set $S$ is expressed as

$$
W=\left\{w_{1}, \cdots, w_{i}, \cdots, w_{n}\right\}, 1 \leq i \leq n
$$

And it satisfies:

$$
w_{1}+\cdots+w_{i} \cdots+w_{n}=1
$$

If the value of the index $s_{i}$ is expressed as $V\left(s_{i}\right)$, its corresponding classical domain is $V\left(s_{o i}\right)=\left[v\left(s_{o i}^{L}\right), v\left(s_{o i}^{R}\right)\right]$,

Then, the extension distance of the index $S_{i}$ is expressed as:

$$
\rho\left(V\left(s_{i}\right), V\left(s_{o i}\right)\right)=\left|V\left(s_{i}\right)-\frac{v\left(s_{o i}^{L}\right)+v\left(s_{o i}^{R}\right)}{2}\right|-\frac{v\left(s_{o i}^{R}\right)-v\left(s_{o i}^{L}\right)}{2}
$$

The extension correlation coefficient of the index $S_{i}$ is expressed as:

$$
K\left(V\left(s_{i}\right)\right)=\rho\left(V\left(s_{i}\right), V\left(s_{o i}\right)\right) /\left|V\left(s_{o i}\right)\right|
$$

In particular, if the extension performance analysis index $S_{i}$ is in the form of an interval set, i.e., $V\left(s_{o i}\right)=\left[v\left(s_{o i}^{L}\right), v\left(s_{o i}^{R}\right)\right], V\left(s_{\otimes i}\right)=\left[v\left(s_{\otimes i}^{L}\right), v\left(s_{\otimes i}^{R}\right)\right]$, and $V\left(s_{o i}\right) \in$ $V\left(s_{i}\right)$, then the extension correlation coefficient can be expressed as:

$$
\begin{aligned}
& K\left(V\left(s_{i}\right)\right)= \\
& \begin{cases}\rho\left(V\left(s_{i}\right), V\left(s_{o i}\right)\right) /\left(\rho\left(V\left(s_{i}\right), V\left(s_{\otimes i}\right)\right)-\rho\left(V\left(s_{i}\right), V\left(s_{o i}\right)\right)\right) & V\left(s_{i}\right) \notin V\left(s_{o i}\right) \\
\rho\left(V\left(s_{i}\right), V\left(s_{o i}\right)\right) /\left(\rho\left(V\left(s_{i}\right), V\left(s_{\otimes i}\right)\right)-\rho\left(V\left(s_{i}\right), V\left(s_{o i}\right)\right)+v\left(s_{o i}^{L}\right)-v\left(s_{o i}^{R}\right)\right) & V\left(s_{i}\right) \in V\left(s_{o i}\right)\end{cases}
\end{aligned}
$$

If the extension correlation coefficient of the performance analysis index ${ }^{s_{i}}$ using the extensible strategy $j$ is recorded as $K_{j}\left(V\left(s_{i}\right)\right)$, then the extension correlation degree of the index under different extensible strategies is given as:

$$
\varphi_{j}\left(V\left(s_{i}\right)\right)= \begin{cases}K_{j}\left(V\left(s_{i}\right)\right) / \max _{x \in X_{0}} K_{j}\left(V\left(s_{i}\right)\right) & K_{j}\left(V\left(s_{i}\right)\right)>0 \\ 0 & K_{j}\left(V\left(s_{i}\right)\right)=0 \\ K_{j}\left(V\left(s_{i}\right)\right) / \max _{x \notin X_{0}}\left|K_{j}\left(V\left(s_{i}\right)\right)\right| & K_{j}\left(V\left(s_{i}\right)\right)<0\end{cases}
$$


Considering the weight of the index $s_{i}$, the comprehensive weighted extension correlation degree of the extension strategy $j$ is shown as:

$$
\phi_{j}=\sum_{i=1}^{n}\left(W_{i} * \varphi_{j}\left(V\left(s_{i}\right)\right)\right), j=1,2, \cdots, m
$$

By setting the threshold $\phi_{o}$ for the selection of extensible strategies for mental health education of college students, the extensible strategy shall be feasible when meeting the condition $\phi_{j} \geq \phi_{o}$.

\section{Conclusion}

This paper mainly studies the extensible strategies for mental health education of college students, and develops a performance analysis model of these extensible strategies. Firstly, the problems in mental health education of college students were enumerated, and extension models were set up for mental health education in colleges, namely compatibility analysis model, matter-element, multi-level diamond-shaped thinking model, and extension transformation. On this basis, the extensible strategies were generated in the four aspects of education techniques, education subjects, education patterns, and education methods for college mental health education. Then, a performance analysis model was presented to effectively select and optimize the extensible strategies. The research results play an important role in supporting the mental health education in colleges. Meanwhile, in this study the selection of extensible strategies for mental health education is based on problems and is guided by extension theory. Therefore, this study also provides a theoretical guide for solving complex problems with extension strategy.

\section{$7 \quad$ Acknowledgement}

This thesis is one of the achievements of Jilin Province's Education Science "Thirteenth Five-Year Plan" 2019 Annual Project "Research on New Paths to Excellent Traditional Cultural Education in Universities from Socialist Core Values".

\section{$8 \quad$ References}

[1] Fusar-Poli, P., Pablo, G. S. D., Micheli, A. D., Nieman, D. H., Correll, C. U., Kessing, L. V., Pfennig, A., Bechdolf, A., Borgwardt, S., Arango, C., Amelsvoort, T. V. (2020). What is good mental health? A scoping review. European Neuropsychopharmacology, 31: 3346. https://doi.org/10.1016/j.euroneuro.2019.12.105.

[2] Rojas, J. R., Coker, T. R. (2015). The Cause and Consequence of Mental Health Problems Among At-Risk Youth. Journal of Adolescent Health, 57(5): 453-454. http://doi.org/10.10 16/j.jadohealth.2015.08.006. 
[3] Fu, Y. J. (2019). The problems and Countermeasures of College Students' mental health education. Contemporary Education Research and Teaching Practice, (21): 216-217. https ://doi.org/ 10.16534/j.cnki.cn13-9000/g.2019.2480.

[4] Ma, L. (2013). Typical psychological problems of college students in the new era and their causes. Journal of Nanchang College of Education, (12): 136-137. https://doi.org/ 10.158 80/j.cnki.zsij.2020.01.086.

[5] Wilk, C. R., Auerbach, R. P., Alonso, J., Benjet, C., Bruffaerts, R., Cuijpers, P., Ebert, D. D., Green, J. G., Mellins, C. A., Mortier, P., Sadikova, E., Sampson, N. A., Kessler, R. C. (2020). The importance of physical and mental health in explaining health-related academic role impairment among college students. Journal of Psychiatric Research, 123: 54-61. https://doi.org/10.1016/j.jpsychires.2020.01.009

[6] Ye, L., Liu, D. F., Dai, Y. T., Zuo, X. Y. (2019). Promote the Multi-dimensional Integration of Ideological and Political Education and Psychological Education in Colleges and Universities. Journal of Anhui University of Technology (Social Sciences), 36(4): 112. https://doi.org/10.3969/j.issn.1671-9247.2019.04.035

[7] Ye, J., Huang, Y. (2019). Exploration of College Students' mental health education from the perspective of positive psychology. Education Modernization, (104): 293-294. https:// doi.org/ 10.16541/j.cnki.2095-8420.2019.104.106.

[8] Kamimura, A., Trinh, H. N., Johansen, M., Hurley, J., Pye, M., Sin, K., Nguyen, H. (2018). Perceptions of mental health and mental health services among college students in Vietnam and the United States. Asian Journal of Psychiatry, 37: 15-19. https://doi.org/10. 1016/j.ajp.2018.07.012.

[9] Zhang, Y., Wang, F. (2018). The construction of network mental health education mode for College Students in Internet plus Era. Western China Quality Education, (12): 80-81. https://doi.org/ 10.16681/j.cnki.wcqe.201823045

[10] Laura, H., Suzanne, D., Wells, J. S. G. (2017). A systematic review of barriers and supports to the participation of students with mental health difficulties in higher education. Mental Health \& Prevention, 6: 26-43. http://doi.org/10.1016/j.mhp.2017.03.002.

[11] Sarah Ketchen, L., Adam, K., Daniel, E., Breland-Noble, A. M. (2018). Mental Health Disparities Among College Students of Color. Journal of Adolescent Health, 63(3): 348356. https://doi.org/10.1016/j.jadohealth.2018.04.014.

[12] Song, L.Q. (2019). The problems and Countermeasures in the mental health education of college students in the new era. Education Modernization, (91): 142-143. https://doi.org/ 1 0.16541/j.cnki.2095-8420.2019.91.068

[13] Yang, Y. C., Lin, G. G. (2020). The Exploration and Practice of Psychological Health Education Reform Based on Psychological Quality Expansion Training - Taking Guangdong Vocational College of Post and Telecom as the Research Object. Journal of Hubei Correspondence University, 33(1): 30-31. https://doi.org/10.3969/j.issn.2096-711X. 2020.01.015.

[14] Sontag-Padilla, L., Dunbar, M. S., Ye, F. F., Kase, C., Fein, R., Abelson, S., Seelam, R., Stein, B. D. (2018). Strengthening College Students' Mental Health Knowledge, Awareness, and Helping Behaviors: The Impact of Active Minds, a Peer Mental Health Organization. Journal of the American Academy of Child \& Adolescent Psychiatry, 57(7): 500-507. https://doi.org/ 10.1016/j.jaac.2018.03.019.

[15] Sarmento, M. (2015). A "Mental Health Profile" of Higher Education Students. Procedia Social and Behavioral Sciences, 191: 12-20. https://doi.org/ 10.1016/j.sbspro.2015.04.606.

[16] Seyedmohammadi, J., Sarmadian, F., Jafarzadeh, A. A., Mcdowell, R. (2019). Development of a model using matter element, AHP and GIS techniques to assess the 
suitability of land for agriculture. Geoderma, 352: 80-95. https://doi.org/10.1016/j.geoder ma.2019.05.046.

[17] Liu, S. L., Li, W. P. (2019). Indicators sensitivity analysis for environmental engineering geological patterns caused by underground coal mining with integrating variable weight theory and improved matter-element extension model. Science of The Total Environment, 686: 606-618. https://doi.org/10.1016/j.scitotenv.2019.04.393.

[18] Chen, R.M., Wang, C.M. (2017). MRI brain tissue classification using unsupervised optimized extenics-based methods. Computers \& Electrical Engineering, 58: 489-501. http ://doi.org/10.1016/j.compeleceng.2017.01.018.

[19] Wang, T., Adeyeye, K., Wang, D. S., Guo, H. B. (2017). The Reconciliation of the Contradictions in the Preservation and Development of Traditional Villages:Refinement of Contradictions through Extenics. Procedia Computer Science, 122: 1149-1155. https://doi. org/10.1016/j.procs.2017.11.485.

[20] Palasundram, K., Sharef, N.M., Nasharuddin, N.A., Kasmiran, K.A., Azman, A. (2019). Sequence to sequence model performance for education chatbot, International Journal of Emerging Technologies in Learning, 14(24): 56-68. https://doi.org/10.3991/ijet.v14i24.121 87

[21] Kang, H., Hong, T., Jung, S., Lee, M. (2019). Technical performance analysis of the smart solar photovoltaic blinds based on the solar tracking methods considering the climate factors. Energy and Buildings, 190: 34-48. https://doi.org/10.1016/j.enbuild.2019.02.013.

[22] Khaldi, L., Iffouzar, K., Ghedamsi, K., Aouzellag, D. (2019). Performance analysis of five-phase induction machine under unbalanced parameters. Journal Européen des Systèmes Automatisés, 52(5): 521-526. https://doi.org/10.18280/jesa.520512

[23] Cigdem, O., Demirele, H. (2018). Performance analysis of different classification algorithms using different feature selection methods on Parkinson's disease detection. Journal of Neuroscience Methods, 309: 81-90. https://doi.org/10.1016/j.jneumeth.2018.08. 017.

[24] Jiang, P., Li, C., Li, R. R., Yang, H. F. (2019). An innovative hybrid air pollution earlywarning system based on pollutants forecasting and Extenics evaluation. KnowledgeBased Systems, 164: 174-192. https://doi.org/10.1016/j.knosys.2018.10.036.

[25] Vladareanu, L., Vladareanu, V., Yu, H.N., Mitroi, D., Ciocîrlan, A.C. (2019). Intelligent Control Interfaces Using Extenics Multidimensional Theory Applied on VIPRO Platforms for Developing the IT INDUSTRY 4.0 Concept. IFAC-PapersOnLine, 52(13): 922-927. https://doi.org/ 10.1016/j.ifacol.2019.11.312.

\section{Author}

Kaixin Gong, an ideological and political educator, has been responsible for psychological health counseling for college students for many years, solving hundreds of cases. also responsible for the employment guidance of college students. Experienced in Participating in the mental health training of provincial college students for many times, responsible for the mental health courses of college students.

Article submitted 2020-02-03. Resubmitted 2020-03-02. Final acceptance 2020-03-05. Final version published as submitted by the authors. 